\title{
Maraena whitefish (Coregonus maraena) larvae reveal enhanced growth during first feeding with live Artemia nauplii
}

\author{
Ralf Bochert, Theresa Horn, Peter Luft
}

Received - 03 January 2017/Accepted - 03 March 2017. Published online: 31 March 2017; @Inland Fisheries Institute in Olsztyn, Poland Citation: Bochert R., Horn T., Luft P. 2017 - Maraena whitefish (Coregonus maraena) larvae reveal enhanced growth during first feeding with live Artemia nauplii - Arch. Pol. Fish. 25: 3-10.

\begin{abstract}
Newly hatched Coregonus maraena (Bloch) larvae reared in aquaria were observed during two trials in 2014 and 2015 for 42 and 34 days after hatching in order to determine the on-feeding effects of different feeding strategies on growth and survival. Feeds of commercial dry feed, live Artemia nauplii, frozen rotifers, and mixtures of these were compared. Larval whitefish were fed brine shrimp for up to 13 days beginning 4 days post hatch (dph). Whitefish larvae fed live Artemia for 8-9 h per day over a period of 10-12 days grew considerably larger (mean value of final total length (TL) 27.3-33.0 mm) and were heavier (mean value of final body weight (BW) 112-165 mg)) than those fed dry feed, frozen rotifers, or Artemia for 3-6 days $(\mathrm{TL}=22.6-30.2 \mathrm{~mm}$; $\mathrm{BW}=$ 50-102 mg). The growth of larvae fed for $24 \mathrm{~h}$ solely on dry food was comparable $(\mathrm{BW}=101 \mathrm{mg}$, $\mathrm{TL}=26.6 \mathrm{~mm})$ at 42 dph. Survival differed among groups (31-63\%) and was highest for larvae fed dry food exclusively. Our results can improve the first feeding of Maraena whitefish larvae in small-scale fish farms.
\end{abstract}

Keywords: on-feeding, larval growth, live feed, dry feed, Maraena whitefish

R. Bochert [ఏ], T. Horn, P. Luft

Mecklenburg-Vorpommern Research Center of Agriculture and Fisheries (LFA MV)

Institute of Fisheries, Research Station Aquaculture, Suedstr. 8, 18375 Born/Darss, Germany

email: r.bochert@lfa.mvnet.de

\section{Introduction}

In the southern Baltic Sea area, Maraena whitefish, Coregonus maraena (Bloch) is a traditional food specialty. Dramatically declining natural catches prompted the initiation of a rehabilitation program in the mid-1990s. Whitefish were bred under aquaculture conditions for restocking. Afterward, the culture of this species as a food fish was started successfully in northeastern Germany mainly in semi-intensive pond systems. Owing to restricted potential for fish farming in open water systems throughout the state of Mecklenburg-Vorpommern, the development of recirculating aquaculture systems (RAS) are the strategic focus. Maraena whitefish, as a local fish species, can be sold for higher market prices than rainbow trout and could, therefore, be a candidate for capital-intensive RAS production. In extensive aquaculture systems, on-feeding of coregonid larvae depends on natural zooplankton production (Luczynski et al. 1986, Rösch and Segner 1990), whereas year-round production of fish in RAS and off-season reproduction requires alternative feeds. Live brine shrimp is commonly used for first larval feeding (Dhont et al. 2013), and they are necessary for the early development of whitefish Coregonus clupeaformis (Mitchill) (Harris 1992). Nevertheless, other species have been tested, for instance the rotifer Brachionus plicatilis (Mahmoudzadeh et al. 2009) or 
the nematode Turbatrix aceti (Hundt et al. 2015). On the other hand, live food production remains labor-intensive and expensive. Alternatively, it is possible to use commercial dry feeds only for the first exogenous feeding of coregonids (Champigneulle and Rojas-Beltran 1990, Rojas-Beltran and Champigneulle 1992, Enz et al. 2001, Leithner and Wanzenböck 2015), but results demonstrate it is necessary to supplement commercial starter feed, for instance, with propionic acid, which is also true in the case of C. maraena (Lahnsteiner and Kletzl 2015). However, small-scale farmers will use commercially available starter feed for larval first feeding because it is readily available. Artemia nauplii are convenient and used widely as live food (Lavens and Sorgeloos 2000), and fish food producers are improving the development of special larval microdiets (Leithner and Wanzenböck 2015) based on present knowledge (Hamre et al. 2013, Rønnestad et al. 2013). This study was conducted to develop a protocol for the first feeding of $C$. maraena larvae in small-scale fish farms without natural zooplankton using commercially available feed. The weight, total length, and survival rates of the larvae were used as the characteristics.

\section{Material and Methods}

\section{Experiment I}

Eggs and sperm of C. maraena taken from wild population in December 2013 were incubated at a mean temperature of $3.8^{\circ} \mathrm{C}$. After hatching, the larvae were acclimated to $15^{\circ} \mathrm{C}$ by increasing the water temperature for five days by two degrees per day. Then they were transferred to the rearing facility to begin feeding trials. Eighteen $10 \mathrm{l}$ plastic containers $(20 \times 30 \times 25 \mathrm{~cm})$ with UV-sterilized, recirculating water were stocked with 200 normally developed larvae each. The water temperature was $15^{\circ} \mathrm{C}$ during the trial which lasted for 37 days (5-42 dph). Six groups (A-F) were randomly distributed in the system to form triplicates. Larvae were fed ad libitum. Groups A-E were fed manually once every $30 \mathrm{~min}$ for $8 \mathrm{~h}$ per day from 07:00 to 15:00. Group F was offered feed once every $30 \mathrm{~min}$ for $24 \mathrm{~h}$ each day by automatic feeder. Two groups were fed commercial larval dry food (DF) type I (particle size 80-200 $\mu \mathrm{m}$; crude protein $58 \%$, crude fat $12 \%$, crude fiber $0.4 \%$, ash $11.7 \%$ ) for 8 hours (group A) and 24 hours (group F) (Table 1). Group B was fed commercial larval diet type II (particle size 100-300 $\mu \mathrm{m}$; crude protein 59\%, crude fat $13 \%$, crude fiber $0.7 \%$, ash $9.3 \%$ ), and group $\mathrm{E}$ was fed frozen rotifers. Groups $\mathrm{C}$ and $\mathrm{D}$ were fed frozen rotifers or live Artemia nauplii for five days followed by five days of a 50:50 mixture with DF type I (Table 1). Live nauplii were supplied ad libitum and dry feed until saturation. From $17 \mathrm{dph}$ until the end of the experiment, all the groups were fed pellet diet type III particle size $0.5-0.8 \mathrm{~mm}$ (crude protein $58 \%$, crude fat $15 \%$, crude fiber $0.4 \%$, ash $11.3 \%$ ). Dead larvae were removed and counted twice daily. The rearing tanks were cleaned daily by siphoning off waste products and any remaining food particles. Prior to the start of the experiment ( 0 and $5 \mathrm{dph}$ ), a subsample of 90 larvae was taken to measure total length (TL) and BW as wet weight (WW) individually. Thirty larvae were pooled and dried at $60^{\circ} \mathrm{C}$ for $48 \mathrm{~h}$ and then weighed. Dry weight (DW) per larvae

Table 1

Feeding scheme during experiment I (March - April 2014) whitefish (C. maraena) larval rearing using different feeds. dph - days post hatch; DF - dry feed types I, II, and III; Rot - frozen rotifers, Art - Artemia nauplii

\begin{tabular}{|c|c|c|c|c|c|c|}
\hline dph & A & B & C & $\mathrm{D}$ & E & $\mathrm{F}$ \\
\hline $6-11$ & $12 \mathrm{~h} \mathrm{DF} \mathrm{I}$ & DF II & Rot & Art & Rot & $24 \mathrm{~h} \mathrm{DF} \mathrm{I}$ \\
\hline $12-16$ & & & Rot/DF I 50:50 & Art/DF I 50:50 & & \\
\hline $17-42$ & & & DF III & & & \\
\hline
\end{tabular}


Table 2

Feeding scheme during experiment II whitefish (C. maraena) larval rearing using different feeds (February - March 2015). All numbers refer to dph - days post hatch; Art - Artemia nauplii; Art/DF - 50:50 mixture of Artemia nauplii with dry diet; DF - dry feed

\begin{tabular}{llllll}
\hline \hline G & H & K & L & M & N \\
\hline \hline Art 4-13 & Art/DF 4-16 & DF & Art 4-5 & Art 4-7 & Art 4-10 \\
& & & Art/DF 6-7 & &
\end{tabular}

Art/DF 8-11

Art/DF 11-13

Art/DF 14-16

all groups DF until 34

was calculated by dividing the results of each measurement by the number of 30 larvae. During the trial $(7,14,21,33,42 \mathrm{dph}), 30$ larvae were sampled from each tank before feeding started. Samples were preserved in $4 \%$ formaldehyde until further examination after a minimum interval of three weeks. Direct observations indicated that there was active feeding behavior throughout the experiment and no deformations were noted.

\section{Experiment II}

In 2014, coregonid larvae were obtained from fertilized eggs of the same origin as in the previous year. Hatching took place in February 2015 after incubation at a mean water temperature of $6.4^{\circ} \mathrm{C}$. Prior to and after hatching, the water temperature was gradually increased to $18^{\circ} \mathrm{C}$ over a period of seven days. This trial started on February 17 with larvae $4 \mathrm{dph}$. The test was conducted in two special small recirculating modules (Kunststoff-Spranger GmbH, Plauen, Germany). Each module contained nine 271 glass aquaria, each of the outlets was protected by a screen. Five-hundred larvae (19 larvae $\mathrm{l}^{-1}$ ) $4 \mathrm{dph}$ were stocked in each of 18 aquaria. Six groups (G-N), each in triplicate, were randomly distributed in the system and were kept for 35 days at a water temperature of $18^{\circ} \mathrm{C}$ and illuminated for 18 hours. All water quality parameters were maintained within safe ranges. Feeding began on $4 \mathrm{dph}$, which was the first day of the experiment. Larvae were fed ad libitum during the day (9 $\mathrm{h}$ per day between 7:30 and 16:30) with Artemia nauplii (SepArt INVE) and a commercial larval diet (particle size 100-200 $\mu \mathrm{m}$; crude protein $56 \%$, crude fat $13 \%$, crude fiber $1.0 \%$, ash $10 \%$ ). Group K was fed exclusively with a dry diet during the experimental period and the remaining groups were fed nauplii combined with the dry diet as follows (Table 2): group $\mathrm{G}-10$ days nauplii and three days a 50:50 mixture of nauplii with the dry diet; group $\mathrm{H}-13$ days 50:50 mixture of nauplii with the dry diet; group L - two days nauplii and two days a 50:50 mixture of nauplii with the dry diet; group M - four days nauplii and four days a 50:50 mixture of nauplii with the dry diet; and group $\mathrm{N}$ - seven days nauplii and three days a 50:50 mixture of nauplii with the dry diet. Until the end of the experiment all the groups were then fed with the dry diet only.

The initial body weight of the larvae was $5.67 \pm$ $0.92 \mathrm{mg} \mathrm{WW}, 10.4 \pm 0.5 \mathrm{~mm}$ TL $(\mathrm{n}=52)$, and 1.31 mg DW (mean of $n=3$ of 30 pooled larvae). Dead larvae were removed daily and counted. The rearing tanks were cleaned daily by siphoning off waste products and any remaining food particles. Subsamples of 15 larvae for measurements (TL, WW, DW) were taken twice weekly before feeding on the morning of the sampling day. Samples were preserved in $4 \%$ formaldehyde and kept for a 
Table 3

Mean total length $( \pm$ SD) of whitefish $($ C. maraena $)$ larvae $(n=30)$ fed different diets in 2014 throughout the experimental period. A-F: different feeding regimes, see Table 1

\begin{tabular}{|c|c|c|c|c|c|c|}
\hline dph & A & B & C & $\mathrm{D}$ & $\mathrm{E}$ & F \\
\hline 0 & $13.2 \pm 0,2$ & & & & & \\
\hline 5 & $13.6 \pm 0,1$ & & & & & \\
\hline 7 & $14.2 \pm 0.6$ & $14.0 \pm 0.6$ & $13.9 \pm 0.5$ & $14.4 \pm 0.6$ & $13.9 \pm 0.6$ & $14.3 \pm 0.5$ \\
\hline 14 & $15.8 \pm 0.7$ & $16.0 \pm 0.7$ & $15.0 \pm 0.6$ & $17.6 \pm 0.9$ & $14.3 \pm 0.5$ & $16.4 \pm 0.9$ \\
\hline 21 & $18.2 \pm 1.1$ & $18.0 \pm 1.1$ & $16.8 \pm 1.0$ & $20.2 \pm 1.3$ & $14.9 \pm 1.0$ & $19.2 \pm 1.2$ \\
\hline 33 & $22.2 \pm 1.9$ & $21.8 \pm 1.8$ & $20.6 \pm 1.5$ & $23.9 \pm 2.4$ & $20.1 \pm 1.5$ & $23.1 \pm 2.2$ \\
\hline 42 & $25.0 \pm 3.2$ & $24.3 \pm 2.7$ & $23.4 \pm 2.5$ & $27.3 \pm 3.5$ & $22.6 \pm 2.2$ & $26.6 \pm 2.7$ \\
\hline
\end{tabular}

Table 4

Mean dry weight $( \pm \mathrm{SD})$ of whitefish $($ C. maraena $)$ larvae $(n=30)$ fed different diets in 2014 throughout the experimental period. A-F: different feeding regimes, see Table 1

\begin{tabular}{|c|c|c|c|c|c|c|}
\hline dph & A & B & C & $\mathrm{D}$ & $\mathrm{E}$ & $\mathrm{F}$ \\
\hline 0 & $1.5 \pm 0.0$ & & & & & \\
\hline 5 & $1.3 \pm 0.0$ & & & & & \\
\hline 7 & $1.2 \pm 0.0$ & $1.3 \pm 0.0$ & $1.2 \pm 0.0$ & $1.4 \pm 0.1$ & $1.2 \pm 0.0$ & $1.4 \pm 0.1$ \\
\hline 14 & $1.9 \pm 0.1$ & $2.0 \pm 0.1$ & $1.4 \pm 0.1$ & $2.7 \pm 0.1$ & $1.0 \pm 0.0$ & $2.5 \pm 0.1$ \\
\hline 21 & $3.1 \pm 0.2$ & $3.1 \pm 0.4$ & $2.3 \pm 0.2$ & $4.5 \pm 0.3$ & $1.5 \pm 0.1$ & $4.1 \pm 0.2$ \\
\hline 33 & $6.8 \pm 0.9$ & $6.1 \pm 0.5$ & $5.1 \pm 0.2$ & $9.0 \pm 0.7$ & $4.8 \pm 0.2$ & $7.6 \pm 1.0$ \\
\hline 42 & $10.1 \pm 2.5$ & $9.2 \pm 2.6$ & $8.2 \pm 3.5$ & $16.0 \pm 4.2$ & $7.1 \pm 0.8$ & $14.1 \pm 0.8$ \\
\hline
\end{tabular}

minimum interval of three weeks until further examination. TL and WW were measured individually and for DW all larvae of the same batch were pooled, dried at $60^{\circ} \mathrm{C}$ for $48 \mathrm{~h}$, and then weighed. Dry weight per larvae was calculated by dividing the results of each measurement by the number of larvae.

\section{Data analysis}

The numbers of survivors per tank were calculated daily by subtracting dead individuals from the initial number minus those collected for measurements. Before any statistical analysis took place, the metric data were checked for normal distribution and for equal variance. In most cases, the data were not normally distributed respectively and had unequal variance. Optionally performed data transformations were not successful (log, square root); therefore, the nonparametric Kruskal-Wallis H-test was used to determine whether the parameters of total length, wet weight, and dry weight differed significantly among treatments at the end of the experiment. The Mann-Whitney U-test was used to identify significant differences between two groups. All statistical analyses (the significance level was $\alpha=0.05$ ) were conducted using SPSS 22.0 (SPSS Inc.). 


\section{Results}

\section{Experiment I}

Larval growth showed clear differences during the experimental period. At $14 \mathrm{dph}$, considerable dissimilarities in TL, WW, and DW were observed among the feeding groups. At the end of the experiment $42 \mathrm{dph}$, group D had the highest values of 27.3 $\mathrm{mm}$ TL followed by group F, whereas the lowest growth performance was recorded in group E (22.6 $\mathrm{mm}$ ) (Table 3). Similar results were found for DW (Table 4). Groups D and F had high final values at $16.0 \mathrm{mg}$ and $14.1 \mathrm{mg}$, respectively, whereas group E was the lightest $(7.1 \mathrm{mg})$. At the end of the experiment, group D, which was fed Artemia and later the dry feed mixture, attained the highest WW (112.5 \pm $54.9 \mathrm{mg})$. This value was not significantly different from group F $(101.9 \pm 37.8 \mathrm{mg})$ or group A $(79.2 \pm$ $39.8 \mathrm{mg}$ ), which was fed dry feed only, because of high variations in values (Fig. 1). In contrast, group E measured $51.3 \pm 19.9 \mathrm{mg}$ and was significantly lighter.

\section{Experiment II}

In the second experiment, $C$. maraena larvae were fed in 2015 with Artemia nauplii and dry feed for different periods (see Table 2). Differences in WW were observed at the earliest at $6 \mathrm{dph}$. After $20 \mathrm{dph}$ until the end of the trial, weight increases were low in groups $\mathrm{K}$ and $\mathrm{L}$, moderate in groups $\mathrm{M}$ and $\mathrm{N}$, and high in groups $\mathrm{G}$ and $\mathrm{H}$. The last two groups were fed at least for ten days with live feed, and they achieved the highest wet masses at the end of the experiment at $158.0 \pm 61.1 \mathrm{mg}(\mathrm{H})$ and $165.6 \pm 79.6 \mathrm{mg}(\mathrm{G})$, respectively (Fig. 2). In contrast, the low performing groups L $(84.3 \pm 42.7 \mathrm{mg})$ and $\mathrm{K}(76.9 \pm 32.7 \mathrm{mg})$, fed Artemia nauplii for a maximum two days, exhibited significant differences in WW. Similar differences were observed for larval length growth (Fig. 3). The mean TL of groups G and H (32.9-33.0 mm) were significantly longer than those of the group $\mathrm{K}$ larvae $(26.3 \mathrm{~mm})$. At the end of the experiment, the highest mean larval DW was also observed in groups G (24.3 mg) and H (23.4 mg) (Fig. 4). The lowest, significantly different mean values were noted in groups L (9.6 mg) and K (10.9 mg). Survival rates varied from 30.9 (L) to $62.5 \%$ (K) (Fig. 5). Contrary to the former results, group $\mathrm{G}$, which performed well, had a low survival rate (33.9\%).

\section{Discussion}

C. maraena larvae clearly differed in growth and survival when fed frozen, live, or commercial feeds. In experiment I, the best growth curves were observed for the group that received live brine shrimp nauplii followed by a mixture with commercial diets before transitioning to dry feed only. The groups receiving dry feed from the beginning of exogenous feeding had similar body weights at the end, but continuous feeding throughout the day was necessary. Frozen rotifers were not suitable as a starter feed for the first ten days, as this resulted in the lowest growth curves for this group. A long phase of feeding Artemia nauplii resulted in the highest growth in experiment II. Body weights, larval dry masses, and total lengths were significantly positively influenced when early stages of Maraena whitefish received live brine shrimp for longer periods. In contrast, the group fed only dry feed, achieved a higher survival rate, whereas growth was the lowest among all the groups.

To date, studies of $C$. maraena first feeding have been rare, but on-feeding experiments were recently carried out by Hundt et al. (2015) and Lahnsteiner and Kletzl (2015). Previous studies on coregonids included commercial feeds (Champigneulle and Rojas-Beltran 1990, Leithner and Wanzenböck 2015), formulated diets (Rösch and Appelbaum 1985, Champigneulle 1988), live natural or single-species zooplankton (Karjalainen 1991, Mahmoudzadeh et al. 2009), different frozen diets (Medgyesy and Wieser 1982, Dabrowski and Poczyczyński 1988), and brine shrimp, Artemia sp. (Drouin et al. 1986, Harris and Hulsman 1991). 


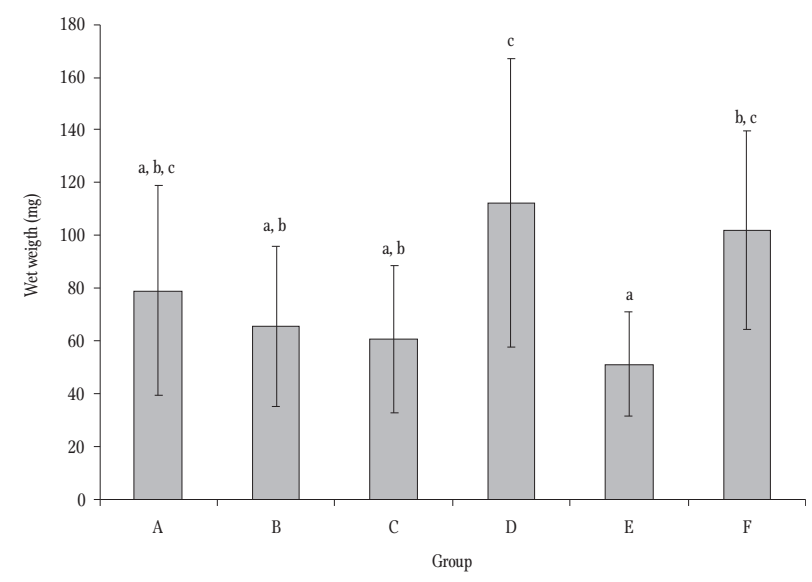

Figure 1. Mean wet weight of whitefish (C. maraena) larvae ( \pm SD) fed different diets in 2014 at the end of the experiment. Different letters show significant $(\mathrm{p}<0.05)$ differences among groups. A-F: different feeding regimes, see Table 1.

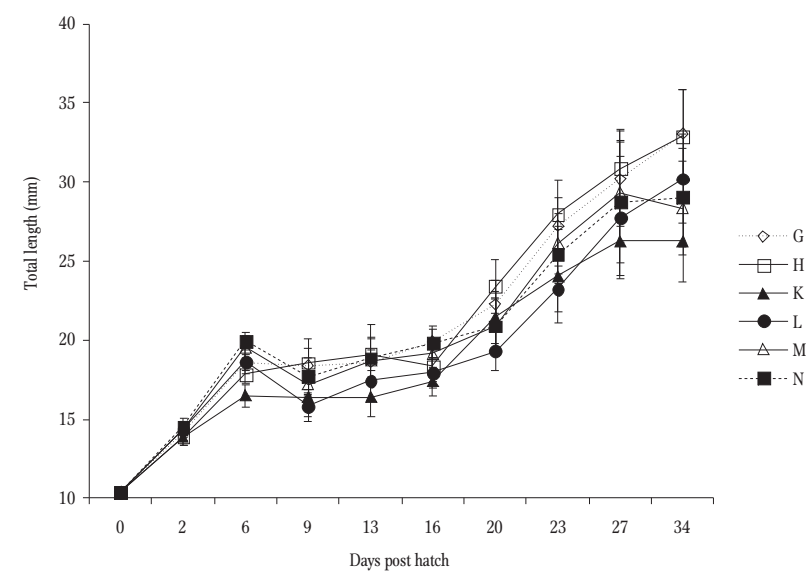

Figure 3. Mean total length of whitefish (C. maraena) larvae ( \pm SD) fed different diets in 2015. G-N: different feeding regimes, see Table 2 .

In most studies on coregonid growth, in which live Artemia nauplii or commercial dry diets were used, water temperatures were kept within a range of 6- $10^{\circ} \mathrm{C}$ (Drouin et al. 1986, Champigneulle and Rojas-Beltran 1990, Harris and Hulsman 1991, Rojas-Beltran and Champigneulle 1992), or $12-15^{\circ} \mathrm{C}$ (Dabrowski et al. 1984, Dabrowski and Kaushik 1985, Drouin et al. 1986, Segner et al. 1988, Champigneulle and Rojas-Beltran 1990, Harris 1992, Enz et al. 2001, Ahmadi et al. 2011). Only a few studies with experimental diets were performed at $17-18^{\circ} \mathrm{C}$ (Dabrowski and Kaushik 1985)

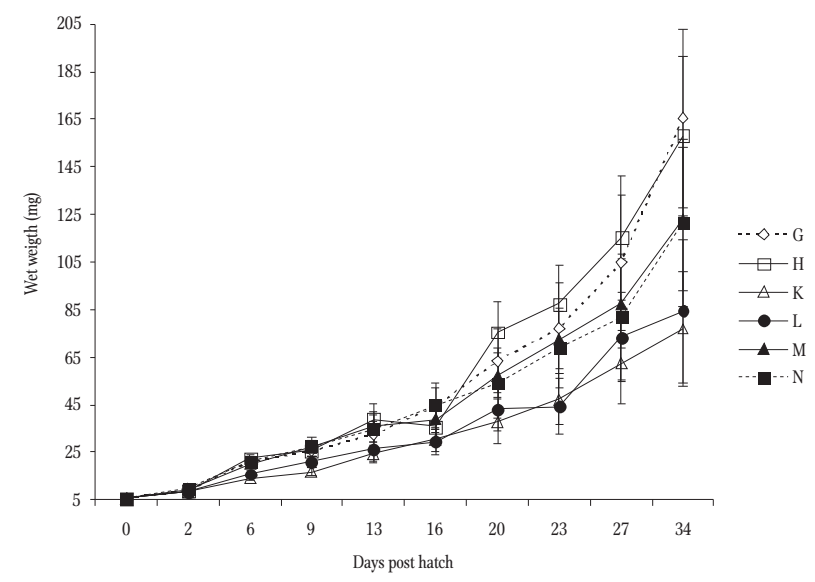

Figure 2. Mean wet weight of whitefish (C. maraena) larvae ( \pm SD) fed different diets in 2015. G-N: different feeding regimes, see Table 2 .

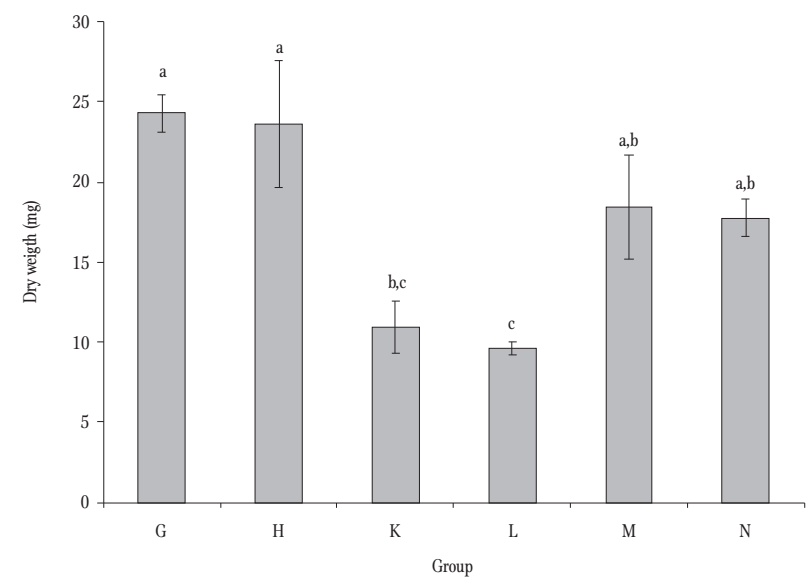

Figure 4. Mean dry weight of whitefish (C. maraena) larvae ( \pm SD) fed different diets in 2015 at the end of the experiment. Different letters show significant $(\mathrm{p}<0.05)$ differences among groups. G-N: different feeding regimes, see Table 2.

and during a short two-week feeding trial with commercial microdiets, live nematodes, and Artemia (Hundt et al. 2015). Larval growth was generally higher in treatments containing brine shrimp compared to all other treatments, and TL was $15.5 \mathrm{~mm}$ on the final $17 \mathrm{dph}$ (Hundt et al. 2015). The results of the present studies, obtained at temperatures of $18^{\circ} \mathrm{C}$ in 2015 , showed faster growth to about $19 \mathrm{~mm}$ TL (Fig. 5). At lower temperatures of $15^{\circ} \mathrm{C}$, larvae reached wet weights of 102-112 mg (Fig. 3), but these findings were strikingly lower than the 160-188 mg WW for whitefish Coregonus schinzi 


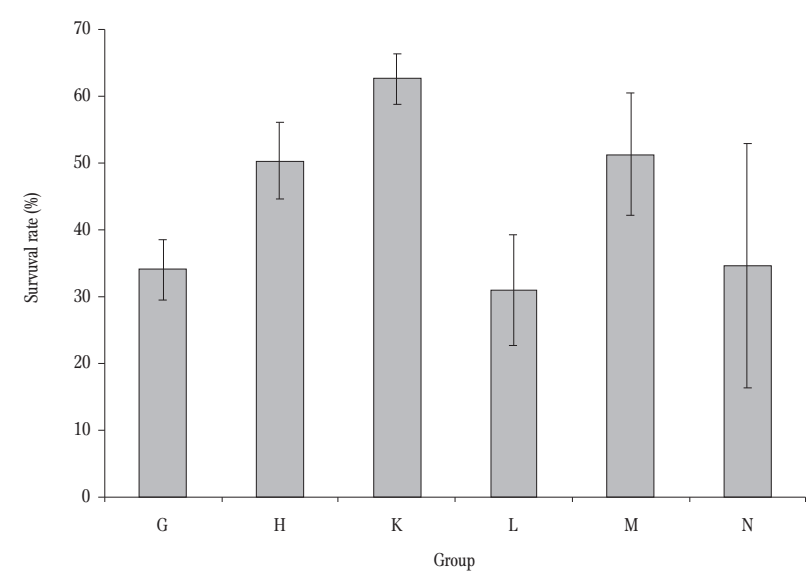

Figure 5. Mean survival rate of whitefish (C. maraena) larvae ( \pm SD) fed different diets in 2015 at the end of experiment. G-N: different feeding regimes, see Table 2.

during a comparable growth period (Dabrowski et al. 1984, Dabrowski and Kaushik 1985). The latter authors noted the best growth rates when the larvae were fed exclusively live Artemia. In that study, the transition from Artemia to dry feed was much better after 14 days (final WW 115-128 mg) than after 21 days (85-117 mg).

Commercial dry diets are generally suitable for the first exogenous feeding of coregonids (Harris 1992, Leithner and Wanzenböck 2015), but results of rearing carried out by other researchers have demonstrated the need for supplementation (Drouin et al. 1986, Zitzow and Millard 1988), which is also the case with C. maraena (Lahnsteiner and Kletzl 2015). Attempts to serve larvae dry diets without such supplementation result in a high incidence of malformations (Harris 1992). In contrast, small-scale fish farmers generally only have access to commercial products and are not able to produce their own specially formulated diets. This is also true for live organisms in intensive aquaculture systems (Mæhre et al. 2013). Natural zooplankton as a food source is limited to local and seasonal occurrence; therefore, Artemia is one of the most common live food species used in larval fish hatchery rearing (Dhont et al. 2013). A recent study indicates that larvae fed compound diets have a 2.5 times higher incidence of mortality than those fed live feed (Sales 2011). Larval survival differs among several studies. Lahnsteiner and Kletzl (2015) report values of $82-85 \%$ for $C$. maraena larvae fed either live zooplankton, commercial, or self-formulated food. Low mortalities were also noted in experiments with powan, Coregonus clupeaformis, (Drouin et al. 1986, Harris and Hulsman 1991), and lavaret, Coregonus lavaretus (L.), (Champigneulle 1988, Rojas-Beltran and Champigneulle 1992). In contrast, very low (<20\%) survival rates were obtained in a study by Luczynski et al. (1986) for peled, Coregonus peled Gmelin, muksun Coregonus muksun (Pall.), and vendace, Coregonus albula (L.). Our findings of moderate survival rates (Fig. 5) are within the range of most previous studies for coregonids (Dabrowski et al. 1984, Dabrowski and Kaushik 1985, Rösch and Appelbaum 1985, Dabrowski and Poczyczyński 1988, Zitzow and Millard 1988, Rösch and Segner 1990, Mahmoudzadeh et al. 2009).

Feeding duration seems to influence significantly whitefish larval performance. Our results indicated higher WW and DW as well as larval TL when dry diets were provided continuously for 24 hours (Tables 3-4, Fig. 1). In this case, growth was only a little slower compared to the group fed with Artemia sp. for up to 10 days. Similar results are reported by Rojas-Beltran and Champigneulle (1992) for lavaret C. lavaretus larvae fed for 9 and 24 hours, respectively, with much better specific growth rates during continuous feeding. The results of these studies show that it is possible to obtain optimal Maraena whitefish larval growth by feeding them live Artemia nauplii for 10-12 days. Nevertheless, they can be grown exclusively on certain dry diets with satisfactory growth rates and survival. Furthermore, these results can help improve Maraena whitefish larval rearing in small-scale fish farms.

Acknowledgments. This study was supported by the European Fisheries Fund (EFF) and the state of Mecklenburg-Vorpommern. The authors give special thanks to technicians Stefan Herper, Daniel Genz, and Rica Tielebier, who ensured throughout the study that all the equipment was fully functional, and they assisted in water analysis and daily cleaning work. 
Author contribution. R.B., T.H. - designed experiment I; P.L. - designed experiment II; R.B., T.H., P.L. - analyzed data; R.B. wrote the paper.

\section{References}

Ahmadi M.R., Mahmoudzadeh H., Babaei M., Shamsaei Mehrjand M. 2011 - Prediction of survival rate in European white fish (Coregonus lavaretus) fry on three different feeding regimes - Iran. J. Fish. Sci. 10: 188-202.

Champigneulle A. 1988 - $A$ first experiment in mass-rearing of coregonid larvae in tanks with a dry food Aquaculture 74: 249-261.

Champigneulle A., Rojas-Beltran R. 1990 - First attempts to optimize the mass rearing of whitefish (Coregonus lavaretus L.) larvae from Léman and Bourget Lakes (France) in tanks and cages - Aquat. Living Resour. 3: 217-228.

Dabrowski K., Charlon N., Bergot P., Kaushik S. 1984 Rearing of coregonid (Coregonus schinzi palea Cuv. et Val.) larvae using dry and live food. I. Preliminary data Aquaculture 41: 11-20.

Dabrowski K.R., Kaushik S.J. 1985 - Rearing of coregonid (Coregonus schinzi palea Cuv. et Val.) larvae using dry and live food. III. Growth of fish and developmental characteristics related to nutrition - Aquaculture 48: 123-135.

Dabrowski K., Poczyczyński P. 1988 - Laboratory experiment and mass rearing of coregonid fish fed exclusively on dry diets - Aquaculture 69: 307-316.

Dhont J., Dierckens K., Støttrup J., Van Stappen G., Wille M., Sorgeloos P. 2013 - Rotifers, Artemia and copepods as live feeds for fish larvae in aquaculture - In: Advances in Aquaculture Hatchery Technology (Ed.) G. Allen, Cambridge, Woodhead Publishing, Woodhead Publishing Series in Food Science, Technology and Nutrition No. 242: 157-202.

Drouin M.A., Kidd R.B., Hynee J.D. 1986 - Intensive culture of lake whitefish (Coregonus clupeaformis Mitchill) using Artemia and artificial feed - Aquaculture 59: 107-118.

Enz C.A., Schäffer E., Müller R. 2001 - Importance of Diet Type, Food Particle Size, and Tank Circulation for Culture of Lake Hallwil Whitefish Larvae - N. Am. J. Aquacult. 63: 321-327.

Hamre K., Yúfera M., Rønnestad I., Boglione C., Conceiçăo L.E.C., Izquierdo M. 2013 - Fish larval nutrition and feed formulation: knowledge gaps and bottlenecks for advances in larval rearing - Rev. Aquac. 5 (Suppl. S1): S26-S58.

Harris K.C. 1992 - Techniques used for the fully - intensive culture of lake whitefish (Coregonus clupeaformis) larvae and yearlings in Ontario, Canada - Pol. Arch. Hydrobiol. 39: 3-4.

Harris K.C., Hulsman P.F. 1991 - Intensive culture of lake whitefish (Coregonus clupeaformis) from larvae to yearling size using dry feeds - Aquaculture 96: 255-268.

Hundt M., Brüggemann J., Grote B., Bischoff A.A., Martin-Creuzburg D., Gergs R., Buck B.H. 2015 - Fatty acid composition of Turbatrix aceti and its use in feeding regimes of Coregonus maraena (Bloch, 1779): is it really a suitable alternative to Artemia nauplii? - J. Appl. Ichthyol. 31: 343-348.

Karjalainen J. 1991 - Survival, growth and feeding of vendace, Coregonus albula (L.), larvae in net enclosures - J. Fish Biol. 38: 905-919.

Lahnsteiner F., Kletzl M. 2015 - On-feeding and juvenile production of coregonid species with formulated dry feeds: effects on fish viability and digestive enzymes - J. Agri. Sci. 7 (11): 48-58.

Lavens P., Sorgeloos P. 2000 - The history, present status and prospect of the availability of Artemia cysts for aquaculture - Aquaculture 181: 397-403.

Leithner S., Wanzenböck J. 2015 - Rearing larvae of different strains of Coregonus lavaretus under cold water conditions: comparison of a special cold-water line with a standard agglomerated microdiet - J. Agri. Sci. 7 (5): 28-36.

Luczynski M., Majkowski P., Bardega R., Dabrowski K. 1986 - Rearing of larvae of four coregonid species using dry and live food - Aquaculture 56: 179-185.

Mahmoudzadeh H., Ahmadi M.R., Shamsaei M. 2009 - Comparison of rotifer Brachionus plicatilis as a choice of live feed with dry feed in rearing Coregonus lavaretus fry Aquacult. Nutr. 15: 129-134.

Mæhre H.K., Hamre K., Elvevoll E.O. 2013 - Nutrient evaluation of rotifers and zooplankton: feed for marine fish larvae - Aquacult. Nutr. 19: 301-311.

Medgyesy N., Wieser W. 1982 - Rearing whitefish (Coregonus lavaretus) with frozen zooplankton by means of a new feeding apparatus - Aquaculture 28: 327-333.

Rojas-Beltran R., Champigneulle A. 1992 - Studies on the improvement of the first feeding on a dry diet for Coregonus lavaretus L. larvae - Aquaculture 102: 319-331.

Rønnestad I., Yúfera M., Ueberschär B., Ribeiro L., Sæle Ø., Boglione C. 2013 - Feeding behaviour and digestive physiology in larval fish: current knowledge, and gaps and bottlenecks in research - Rev. Aquac. 5 (Suppl. S1): S59-S98.

Rösch R., Appelbaum S. 1985 - Experiments on the suitability of dry food for larvae of Coregonus lavaretus L. Aquaculture 48: 291-302.

Rösch R., Segner H. 1990 - Development of dry food for larvae of Coregonus lavaretus L. I. Growth, food digestion and fat absorption - Aquaculture 91: 101-115.

Sales J. 2011 - First feeding of freshwater ?sh larvae with live feed versus compound diets: a meta-analysis - Aquacult. Int. 19: 1217-1228.

Segner H., Rösch R., Schmidt H., von Poeppinghausen K.J. 1988 - Studies on the suitability of commercial dry diets for rearing of larval Coregonus lavaretus from Lake Constance - Aquat. Living Resour.. 1: 231-238.

Zitzow R.E., Millard J.L. 1988 - Survival and growth of lake whitefish (Coregonus clupeaformis) larvae fed only formulated dry diets - Aquaculture 69: 105-113. 